\title{
Secreted and Cell-Associated Adenylate Kinase and Nucleoside Diphosphokinase Contribute to Extracellular Nucleotide Metabolism on Human Airway Surfaces
}

\author{
Scott H. Donaldson, Maryse Picher, and Richard C. Boucher \\ Cystic Fibrosis Research and Treatment Center and Department of Medicine, University of North Carolina at Chapel Hill, Chapel Hill,
} North Carolina

\begin{abstract}
5 '-Nucleoside triphosphates (NTP) are present in the liquid covering airway surfaces and mediate important physiologic events through their interaction with P2-nucleotide receptors. Activation of airway $\mathrm{P}_{2} \mathrm{Y}_{2}$ receptors, for example, stimulates ciliary beat frequency, chloride/liquid secretion, and goblet cell degranulation. We, therefore, have studied the metabolic pathways that regulate the concentration of nucleotides on airway surfaces. Stimulation of submucosal gland secretion in the nose was previously found to decrease the concentration of $5^{\prime}$-adenosine triphosphate (ATP) in nasal lavage samples due to the presence of a secreted 5'-nucleoside triphosphatase (NTPase). In this study, gland secretions were further studied and found to also contain adenylate kinase (AK) and nucleoside diphosphokinase (NDPK) activities. Ecto-AK and ecto-NDPK activities were also detected in well-differentiated cultures of superficial nasal epithelia, which reflected a combination of cell-associated and released (into culture media) AK and NDPK activities. This study demonstrates that "ecto-kinases" on airway surfaces (1) emanate from different enzyme families, including both AK and NDPK; (2) are expressed at superficial epithelial surfaces and in submucosal glands; and (3) may be important regulators of nucleotide concentrations on airway surfaces.
\end{abstract}

Extracellular P2X and P2Y nucleotide receptors are widely expressed throughout the body and mediate a wide array of physiologic processes. The $\mathrm{P}_{2} \mathrm{Y}_{2}$ subtype appears to be the dominant apical membrane nucleotide receptor in the airway epithelia of the lung (1). This G-protein-coupled receptor activates phospholipase $\mathrm{C}$ and increases intracellular calcium in response to luminal adenosine $5^{\prime}$-triphosphate (ATP) or uridine $5^{\prime}$-triphosphate (UTP) $(2,3)$. Important cellular events that are mediated by $\mathrm{P}_{2} \mathrm{Y}_{2}$ receptor activation in airway epithelia include chloride secretion (4), acceleration of ciliary beat frequency (5), and induction of mucus secretion by goblet cells (6). The net effect of these cellular events on airways physiology is accelerated mucociliary clearance (7). Consequently, the $\mathrm{P} 2 \mathrm{Y}_{2}$ receptor system has received attention as an endogenous regulator of mucociliary clearance and as a potential therapeutic target for diseases characterized by poor mu-

(Received in original form June 13, 2001 and in revised form October 17, 2001) Address correspondence to: Scott H. Donaldson, M.D., University of North Carolina at Chapel Hill, Cystic Fibrosis/Pulmonary Research and Treatment Center, 6019 Thurston Bowles Building, CB\# 7248, Chapel Hill, North Carolina 27599, E-mail: Scott_Donaldson@med.unc.edu

Abbreviations: adenylate kinase, AK; airway surface liquid, ASL; adenosine triphosphate, ATP; cystic fibrosis, CF; epithelial growth factor, EGF; high-performance liquid chromatography, HPLC; nucleoside diphosphokinase, NDPK; 5' -nucleoside triphosphate(s), NTP; $5^{\prime}$-nucleotide triphosphatase, NTPase; submucosal gland, SMG; uridine 5' triphosphate, UTP.

Am. J. Respir. Cell Mol. Biol. Vol. 26, pp. 209-215, 2002

Internet address: www.atsjournals.org cociliary clearance, such as cystic fibrosis $(\mathrm{CF})$. In addition, the P2X family of receptors may modulate chloride secretion and ciliary beat frequency and has been proposed as potential therapeutic targets for $\mathrm{CF}$ lung disease $(8,9)$.

If the $\mathrm{P}_{2} \mathrm{Y}_{2}$ receptor is indeed involved in the endogenous regulation of mucociliary clearance, regulation of extracellular $5^{\prime}$-nucleotide levels is likely an important physiologic process that will reflect the balance between nucleotide release and metabolism. In a recent study, we demonstrated that the $\mathrm{P}_{2} \mathrm{Y}_{2}$ receptor agonist ATP was detectable in human nasal airway surface liquid (ASL) under basal conditions at a physiologically relevant concentration. The superficial epithelium exhibited the capacity to increase ATP levels in ASL via nucleotide release and to decrease nucleoside 5' -nucleoside triphosphate (NTP) levels via cell surface nucleotidases. Interestingly, when studying the impact of submucosal gland (SMG) secretions on ASL nucleotide concentrations, a $5^{\prime}$-nucleoside triphosphatase (NTPase) activity was observed in nasal lavages enriched with gland secretions (10).

In the present study, we have investigated the profile of nucleotide-metabolizing enzymes present in both human SMG secretions and on superficial epithelial surfaces. In contrast to traditional paradigms of extracellular nucleotide metabolism that focus on dephosphorylation of nucleotides, our data suggest that adenylate kinase (AK) and nucleoside diphosphokinase (NDPK) play a role in the interconversion and metabolism of extracellular nucleotides on airway surfaces.

\section{Materials and Methods \\ Subjects}

Submucosal gland secretions were collected as outlined below from normal $(n=5$; age $32.6 \pm 1.7 \mathrm{yr})$ subjects without visible nasal inflammation or recent nasal symptoms after obtaining informed consent in accordance with the University of North Carolina Human Rights Committee.

\section{Collection of Nasal Submucosal Gland Secretions}

To study enzyme activities in SMG secretions, a baseline nasal lavage was performed by delivering a total of $2 \mathrm{ml}$ of $0.9 \%$ saline to one nasal cavity with a medication dispenser (100 $\mu 1 /$ actuation $)$. The lavage was recovered by expelling the liquid from the nose into a sterile specimen cup after every five actuations. To obtain a lavage enriched with SMG secretions, the same nostril was dosed with methacholine via nebulizer $(30 \mathrm{mg} / \mathrm{dose} ; 100 \mathrm{mg} / \mathrm{ml}$ in $0.9 \% \mathrm{NaCl}$ ), followed two minutes later by a lavage as described above. To test the specificity of methacholine-induced effects, the opposite nostril was pretreated with ipratropium bromide 
(168 $\mu \mathrm{g} ; 42 \mu \mathrm{g} /$ actuation), an acetylcholine receptor antagonist, followed $15 \mathrm{~min}$ later by dosing with methacholine $(30 \mathrm{mg})$. Two minutes after methacholine administration, the nostril was lavaged as described above. The volume of each lavage return was measured, mixed 1:1 with a Tris buffer solution (in $\mathrm{mM}$ : Tris $\mathrm{HCl}$ $100, \mathrm{MgCl}_{2}$ 2, DTT 3; pH 7.4), and incubated $\left(37^{\circ} \mathrm{C} ; 30 \mathrm{~min}\right)$ with intermittent vortexing to aid the dissolution of mucinous secretions. The solutions were then centrifuged $(5 \mathrm{~min} ; 600 \times g)$ to remove cells and undissolved particulate matter.

\section{Enzyme Assays in Nasal Lavage Samples}

All assays were performed using $0.1 \mathrm{ml}$ of lavage solution at $37^{\circ} \mathrm{C}$. Reactions were started with the addition of substrate and stopped with $0.5 \mathrm{ml}$ of cold $5 \%$ trichloroacetic acid (TCA). Inhibitors were added $15 \mathrm{~min}$ before the start of the reaction. TCA was extracted from the samples using 8 vol of ethyl ether. Initial rates of reaction were determined using conditions that ensured $<10 \%$ metabolism of the added substrate had occurred.

\section{Adenylate Kinase Assays}

The forward $\left(\left[\gamma^{33} \mathrm{P}\right] \mathrm{ATP}+\mathrm{AMP} \rightarrow\left[\beta^{33} \mathrm{P}\right] \mathrm{ADP}+\mathrm{ADP}\right)$ and reverse $\left(\left[{ }^{3} \mathrm{H}\right] \mathrm{ADP} \rightarrow\left[{ }^{3} \mathrm{H}\right] \mathrm{AMP}+\left[{ }^{3} \mathrm{H}\right] \mathrm{ATP}\right)$ adenylate kinase reactions were studied in lavage fluids using high-performance liquid chromatography (HPLC). To measure maximal reaction rates, [ $\left.{ }^{3} \mathrm{H}\right] \mathrm{ADP}$ was added to lavage solutions $(0.5 \mathrm{mM}$ final concentration; $0.5 \mu \mathrm{Ci} /$ sample) at $37^{\circ} \mathrm{C}$. Aliquots were assayed at multiple time points $(\mathrm{t}=0,2,5$, and $10 \mathrm{~min})$ to ensure that initial rates of reaction were obtained. The rate of $\left[{ }^{3} \mathrm{H}\right]$ AMP accumulation directly reflected adenylate kinase activity because (1) no ADPase activity was observed in nasal lavage samples after inhibiting $\mathrm{AK}$ with diadenosine pentaphosphate $\left(\mathrm{AP}_{5} \mathrm{~A}\right)$ (Figure $2 \mathrm{C}$ ), and (2) no significant AMP hydrolysis was observed over comparable time intervals (Figure $2 \mathrm{~B}$ ). $\left[{ }^{3} \mathrm{H}\right] \mathrm{UDP}$ as an enzyme substrate was tested in an identical fashion. The effect of $\mathrm{AP}_{5} \mathrm{~A}(1 \mathrm{mM})$, a specific adenylate kinase inhibitor (11), was also tested.

\section{Nucleoside Diphosphokinase Assays}

The formation of $\left[{ }^{3} \mathrm{H}\right]$ ATP from unlabeled ATP $(0.5 \mathrm{mM})$ and $\left[{ }^{3} \mathrm{H}\right] \mathrm{ADP}(0.1 \mathrm{mM})$ was assessed with HPLC and quantitated as an indicator of NDPK activity. $\mathrm{AP}_{5} \mathrm{~A}(1 \mathrm{mM})$ was included in these reactions to eliminate $\left[{ }^{3} \mathrm{H}\right]$ ATP formation via AK. Multiple samples $(\mathrm{t}=0,0.5,1,2,5$, and $15 \mathrm{~min})$ were collected to measure the initial rate of reaction in nasal lavages performed after designated treatments. The presence of NDPK was further assessed by the formation of $\left[\gamma^{33} \mathrm{P}\right] \mathrm{UTP}$ from $\left[\gamma^{33} \mathrm{P}\right] \mathrm{ATP}(0.5 \mathrm{mM})$ and UDP $(0.1 \mathrm{mM})$.

\section{Cell Culture}

Well-differentiated primary cultures of the superficial nasal epithelia lining were grown as previously described (12). In brief, primary nasal epithelial cells were harvested from resected surgical specimens by protease digestion, plated on porous Transwell Col filters (well diameter, $12 \mathrm{~mm}$; pore size, $0.45 \mu \mathrm{m}$; Corning Costar, Aston, MA) and grown under air-liquid interface conditions. The culture medium contained a 50:50 mixture of LHC Basal (Biofluids, Inc., Rockville, MD) and Dulbecco's modified Eagle's medium-High glucose media (Biofluids, Inc.), $5 \mu \mathrm{g} / \mathrm{ml}$ insulin, $0.072 \mu \mathrm{g} / \mathrm{ml}$ hydrocortisone, $0.5 \mathrm{ng} / \mathrm{ml}$ epithelial growth factor (EGF), $10 \mathrm{nM} \mathrm{T}_{3}, 10 \mu \mathrm{g} / \mathrm{ml}$ transferrin, $0.6 \mu \mathrm{g} / \mathrm{ml}$ epinephrine, 0.5 $\mu \mathrm{M}$ phosphoethanolamine, $0.5 \mu \mathrm{M}$ ethanolamine, $50 \mathrm{nM}$ retinoic acid, $0.5 \mathrm{mg} / \mathrm{ml}$ bovine serum albumin, $0.8 \%$ bovine pituitary extract, trace elements (1X; Biofluids Inc.), Stock 4 (1X; Biofluids, Inc.), Stock 11 (Biofluids, Inc.), $50 \mathrm{U} / \mathrm{ml}$ penicillin, and $50 \mu \mathrm{g} / \mu \mathrm{l}$ streptomycin. Enzyme assays were performed after 4 wk of confluence. Under these conditions cultures were composed mainly of ciliated cells $(>90 \%)$ and exhibited a transepithelial electrical resistance of at least $300 \Omega / \mathrm{cm}^{2}$.

\section{Enzyme Assays on Cell Cultures}

The apical surface of primary cultures of human nasal epithelial cells was rinsed three times with Krebs buffer (KBR [in mM]: 140 $\mathrm{Na}^{+}, 120 \mathrm{Cl}^{-}, 5.2 \mathrm{~K}^{+}, 25 \mathrm{HCO}_{3}, 2.4 \mathrm{HPO}_{4}{ }^{-}, 1.6 \mathrm{Ca}^{2+}, 1.6 \mathrm{Mg}^{2+}$, 5.2 glucose, and 25 HEPES [pH 7.4]), and preincubated with KBR (0.35 ml mucosal/serosal) for $30 \mathrm{~min}$ at $37^{\circ} \mathrm{C}\left(5 \% \mathrm{CO}_{2} / 95 \% \mathrm{O}_{2}\right)$. AK and NDPK activity on the mucosal surface was then measured. AK activity was quantitated after adding $0.1 \mathrm{mM}\left[\gamma^{32} \mathrm{P}\right] \mathrm{ATP}+$ $0.1 \mathrm{mM}$ AMP. NDPK activity was measured using $0.3 \mathrm{mM}$ $\left[\gamma^{32} \mathrm{P}\right] \mathrm{ATP}+0.1 \mathrm{mM}$ UDP in the presence of $1 \mathrm{mM} \mathrm{Ap}{ }_{5} \mathrm{~A}$ to inhibit AK activity. All reactions were initiated by the addition of the substrate(s) and stopped by transferring $10 \mu \mathrm{l}$ aliquots to tubes containing $0.3 \mathrm{ml}$ ice-cold water. The samples were boiled for $3 \mathrm{~min}$, filtered, and analyzed by HPLC.

\section{Cell Culture Enzyme Release Assays}

Experiments were conducted to investigate whether nasal epithelial cells released ecto-enzymes into the mucosal bath. Cell surfaces were rinsed three times with KBR and incubated $(0.35 \mathrm{ml}$ mucosal/serosal $)$ at $37^{\circ} \mathrm{C}\left(5 \% \mathrm{CO}_{2} / 95 \% \mathrm{O}_{2}\right)$. The conditioned medium was collected at various time points and assayed for $\mathrm{AK}$ and NDPK activities as described above for cell surface assays.

\section{HPLC Analysis}

Nucleotides were separated by HPLC via a Hypersil SAX column (Bodman, Aston, PA) using a two solvent system consisting of buffer A (5 mM NH $\left.\mathrm{H}_{2} \mathrm{PO}_{4}, \mathrm{pH} 2.8\right)$ and buffer $\mathrm{B}(375 \mathrm{mM}$ $\left.\mathrm{NH}_{4} \mathrm{H}_{2} \mathrm{PO}_{4}, \mathrm{pH} 3.7\right)$. A linear gradient was developed from $100 \%$ buffer $\mathrm{A}$ to $80 \%$ buffer $\mathrm{B}$ over the first $13 \mathrm{~min}$, followed by an additional $7 \mathrm{~min}$ of $100 \%$ buffer A. Absorbance at $264 \mathrm{~nm}$ was monitored with an SPD10A UV detector (Shimadzu; Columbia, MD), and radioactivity was measured online with a Flo-One detector (Packard; Meridan, CT).

\section{Materials}

All NTPases, including radiolabeled ATP and UTP, were obtained from Amersham Pharmacia (Piscataway, NJ). Tritium labeled ADP and UDP were prepared from the corresponding $\left[{ }^{3} \mathrm{H}\right]$ NTP precursor by incubating the appropriate substrate with hexokinase (Roche Molecular Biochemicals; Indianapolis, IN) and glucose $(25 \mathrm{mM})$ for $1 \mathrm{~h}$ at $37^{\circ} \mathrm{C}$, followed by heat inactivation of hexokinase by boiling for $2 \mathrm{~min}$. Complete conversion to the appropriate $\left[{ }^{3} \mathrm{H}\right]$-nucleoside diphosphate (NDP) was confirmed using HPLC. For in vivo nasal studies, methacholine was purchased from Amend Drug and Chemical (Irvington, NJ), and ipratropium bromide from Boehringer Ingelheim (Ridgefield, CT). All other reagents were purchased from Sigma (St. Louis, MO).

\section{Statistics}

Unless otherwise stated, data are reported as mean \pm SE. Comparisons were made with the Student's $t$ test, with $P<0.05$ considered significant.

\section{Results}

\section{5'-Nucleoside Triphosphate and Diphosphate Metabolism in Gland Secretions}

We have previously shown that the concentration of ATP in nasal lavages obtained after stimulating SMG secretion is markedly reduced due to the presence of a secreted NTPase (10). To further characterize the metabolic fate of exogenously added nucleoside triphosphates, $\left[{ }^{3} \mathrm{H}\right]$ ATP and $\left[{ }^{3} \mathrm{H}\right]$ UTP were added to lavages enriched with SMG secretions (Figure 1). After the addition of $\left[{ }^{3} \mathrm{H}\right] \mathrm{ATP}, \mathrm{ADP}$ and then AMP were formed, with little adenosine formation, 


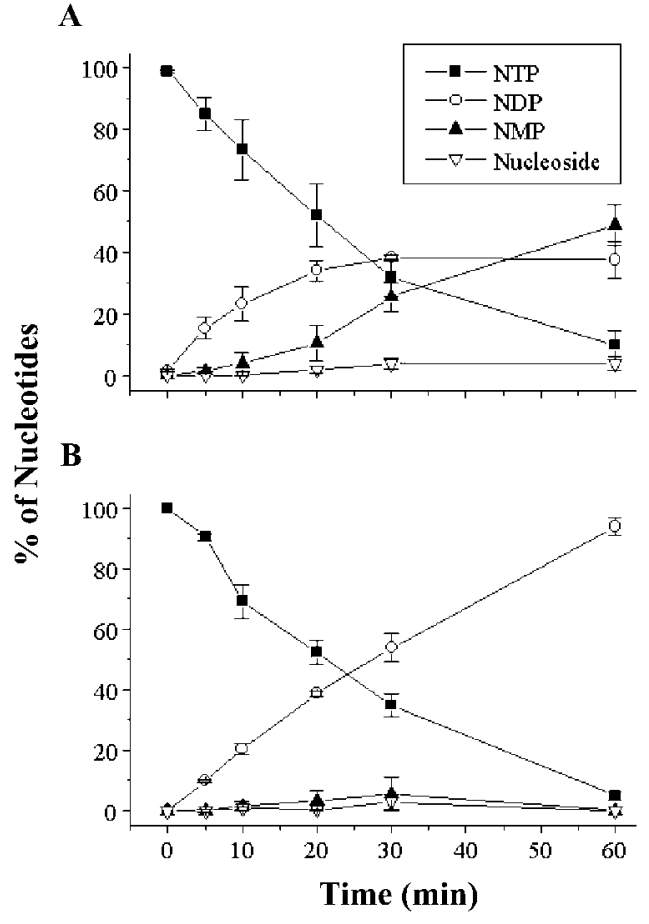

Figure 1. The pattern of NTP metabolism in SMG secretions. (A) $\left[{ }^{3} \mathrm{H}\right]$ ATP or $(B)\left[{ }^{3} \mathrm{H}\right] \mathrm{UTP}(100 \mu \mathrm{M})$ were added to nasal lavages samples collected after stimulating nasal submucosal gland secretion with methacholine. The formation of metabolic products was monitored with HPLC over time (closed squares, NTP; open circles, NDP; closed triangles, NMP; open triangles, adenosine/uridine).

over time. In contrast, the addition of [ $\left.{ }^{3} \mathrm{H}\right] \mathrm{UTP}$ led mainly to the accumulation of $\left[{ }^{3} \mathrm{H}\right]$ UDP with little $\left[{ }^{3} \mathrm{H}\right] \mathrm{UMP}$ formation. The different rates of AMP and UMP formation from their respective NTPs, despite similar disappearance rates of ATP and UTP, suggested that SMG secretions might contain a complex mixture of enzymes, rather than a single enzyme.

\section{Adenylate Kinase Activity in Nasal Submucosal Gland Secretions}

To further investigate the nature of NDP metabolism in SMG secretions, $\left[{ }^{3} \mathrm{H}\right]$ ADP and $\left[{ }^{3} \mathrm{H}\right]$ UDP $(100 \mu \mathrm{M})$ were added as starting substrates. As predicted from the patterns of ATP and UTP metabolism (Figure 1), the metabolism of $\left[{ }^{3} \mathrm{H}\right]$ ADP occurred much more rapidly than that of $\left[{ }^{3} \mathrm{H}\right] \mathrm{UDP}$ $(54.7 \pm 2.3 \%$ versus $6.6 \pm 3.6 \%$ metabolized over $15 \mathrm{~min}$, respectively) (Figure 2). Interestingly, the disappearance of $\left[{ }^{3} \mathrm{H}\right]$ ADP was associated not only with $\left[{ }^{3} \mathrm{H}\right]$ AMP formation, but also with the appearance of a second peak that ran precisely at the location of $\left[{ }^{3} \mathrm{H}\right] \mathrm{ATP}$. Based on this observation, we hypothesized that AK was responsible for ADP metabolism in nasal lavage samples.

To test this notion further, we preincubated lavage solutions with diadenosine pentaphosphate $\left(\mathrm{AP}_{5} \mathrm{~A}\right)$, a competitive inhibitor of adenylate kinase (11), before examining $\mathrm{ADP}$ metabolism. $\mathrm{AP}_{5} \mathrm{~A}$ itself was not metabolized (data not shown), but did completely block the metabolism of $\left[{ }^{3} \mathrm{H}\right]$ ADP (Figure 2C). $\left[{ }^{3} \mathrm{H}\right]$ UDP metabolism was notably slower than that of $\left[{ }^{3} \mathrm{H}\right] \mathrm{ADP}$ and was also inhibited by $\mathrm{AP}_{5} \mathrm{~A}$ (Figures $2 \mathrm{E}$ and $2 \mathrm{~F}$ ).

As another test for the presence of AK activity in SMG secretions, we added $\left[\gamma^{33} \mathrm{P}\right] \mathrm{ATP}$ and either AMP or UMP to lavage solutions. The formation of $\left.{ }^{33} \mathrm{P}\right] \mathrm{ADP}$ from $\left[\gamma^{33} \mathrm{P}\right] \mathrm{ATP}$ and AMP did indeed occur in an $\mathrm{AP}_{5} \mathrm{~A}$ sensitive manner (Figures 3A-3C), confirming the presence of a NMPK activity. The formation of $\left[{ }^{33} \mathrm{P}\right] \mathrm{UDP}$ from $\left[\gamma^{33} \mathrm{P}\right] \mathrm{ATP}$ and UMP was very slow (Figure 3D) and blocked by $\mathrm{AP}_{5} \mathrm{~A}$ (Figure $3 \mathrm{E}$ ). The transphosphorylation of AMP by ATP (Figure 3B), with poor UMP utilization (Figure 3D), is consistent with the substrate specificity of most AK isoforms (AK1, AK2, AK4, and AK5) and rules out other nucleoside monophosphate kinase family members (13).

Using $\left[{ }^{3} \mathrm{H}\right] \mathrm{ADP}$ as the starting substrate, we quantified AK activity in SMG secretions (Figure 3F). With saturating substrate concentrations and short time intervals, the production of $\left[{ }^{3} \mathrm{H}\right] \mathrm{AMP}$ directly reflected AK activity because ADP metabolism was entirely $\mathrm{AP}_{5} \mathrm{~A}$ sensitive and no AMP degradation occurred under these conditions (Figure 2). Note that the formation of ATP from ADP did not quantitatively reflect AK activity due to the concomitant presence of an NTPase (Figure 1). The AK activity in lavages enriched with SMG secretions was $\sim 9$-fold higher than in control lavages $(P<0.001)$. Pretreatment with ipratropium markedly reduced the methacholine-induced increase in AK activity, $(P=0.01)$.

\section{Nucleoside Diphosphokinase Activity in Nasal Submucosic} Gland Secretions

NDPK, which catalyzes the transfer of the $\gamma$-phosphate group from a NTP donor molecule to a NDP acceptor, is generally known as an intracellular enzyme responsible for balancing the intracellular pool of available NTPs (14). Recent work by Lazarowski and colleagues, however, demonstrated that an NDPK activity is present on the apical surface of a variety of cell lines, including a human bronchial epithelial cell line, and is able to interconvert NTPs in the extracellular milieu $(15,16)$. We hypothesized that SMG secretions might also contain this enzyme. We therefore performed NDPK assays on control lavages (no methacholine treatment), after methacholine treatment, and after ipratropium bromide plus methacholine.

NDPK activity was present in nasal lavages, as demonstrated by the transfer of the terminal phosphate group from $\left[{ }^{33} \mathrm{P}\right] \gamma \mathrm{ATP}$ to UDP, forming $\left[{ }^{33} \mathrm{P}\right] \gamma \mathrm{UTP}$, and by the formation of $\left[{ }^{3} \mathrm{H}\right]$ ATP from $\left[{ }^{3} \mathrm{H}\right]$ ADP + ATP (in the presence of $\mathrm{AP}_{5} \mathrm{~A}$, to eliminate competition with $\mathrm{AK}$ ) (Figures 4A-4D). Because an NTPase is also present in SMG secretions, the measured formation of labeled NTP underestimates the true NDPK activity present in these lavage solutions. Despite this limitation, $\left[{ }^{3} \mathrm{H}\right] \mathrm{ADP}$ was converted to $\left[{ }^{3} \mathrm{H}\right]$ ATP in the presence of unlabeled ATP and excess $\mathrm{AP}_{5} \mathrm{~A}$ at $10.7 \mathrm{nmol} / \mathrm{min} / \mathrm{ml}$ in lavages enriched with $\mathrm{SMG}$ secretions (Figure 4E). This represents a 4-fold increase in comparison with control lavages $(P<0.001)$. Once again, pretreatment with ipratropium bromide inhibited the subsequent increase in NDPK activity in lavages after methacholine treatment $(P=0.02)$. 

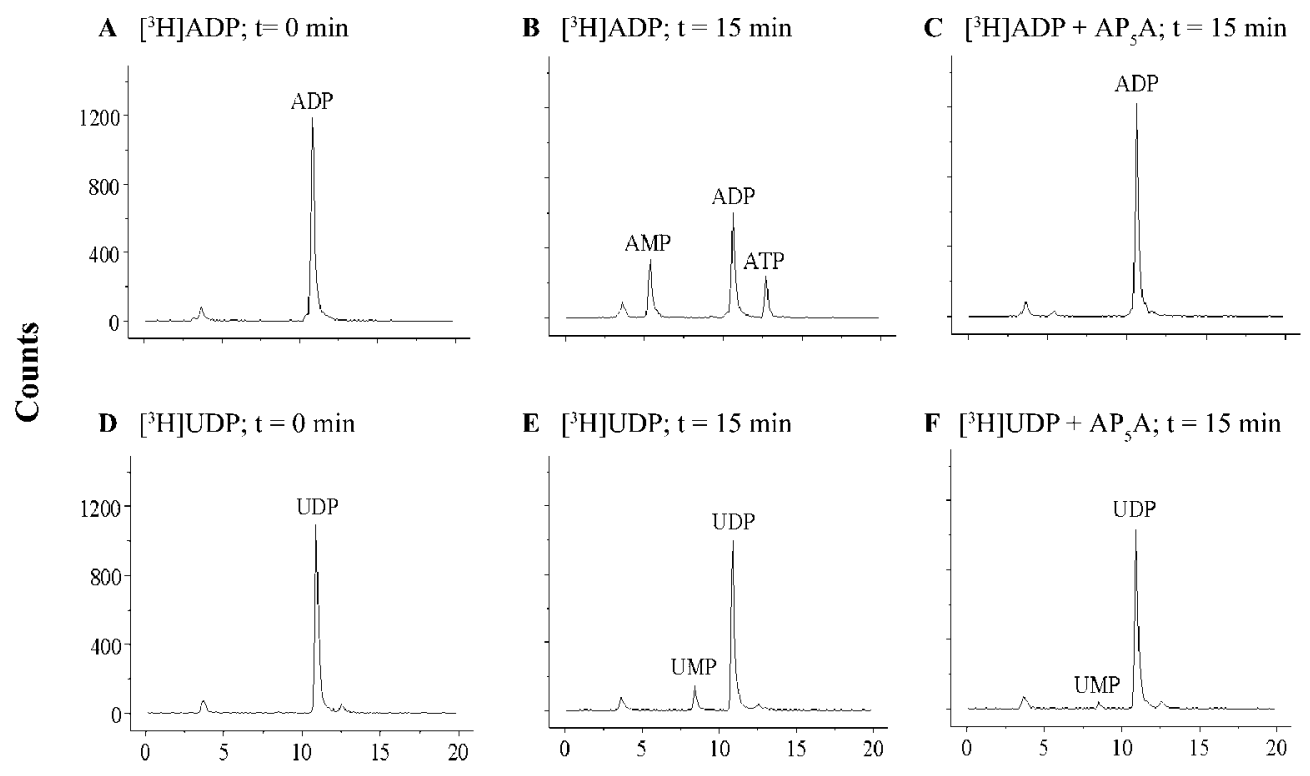

Figure 2. NDP Metabolism and in SMG Secretions. $(A)\left[{ }^{3} \mathrm{H}\right] \mathrm{ADP}$ or $(D)\left[{ }^{3} \mathrm{H}\right] \mathrm{UDP}(0.1 \mathrm{mM})$ were added to nasal lavages enriched with SMG secretions at $t=0 \mathrm{~min}$. (B) The conversion of $\left[{ }^{3} \mathrm{H}\right] \mathrm{ADP}$ to $\left[{ }^{3} \mathrm{H}\right] \mathrm{ATP}$ and $\left[{ }^{3} \mathrm{H}\right] \mathrm{AMP}$ at $t=$ $15 \mathrm{~min}$ is shown, whereas $(E)$ minimal $\left[{ }^{3} \mathrm{H}\right]$ UDP metabolism occurred over this time interval. The $\mathrm{AK}$ inhibitor $\mathrm{AP}_{5} \mathrm{~A}(500 \mu \mathrm{M})$ blocked the metabolism of $(C)$ $\left[{ }^{3} \mathrm{H}\right]$ ADP and $(F)\left[{ }^{3} \mathrm{H}\right] \mathrm{UDP}$.

Retention Time (min)

\section{AK and NDPK Activity on Superficial Airway Epithelial Surfaces}

The presence of AK and NDPK activity in SMG secretions suggested that these enzymes might play a role in superficial airway epithelial extracellular nucleotide metabolism. We therefore used well-differentiated airway epithelial cultures to determine whether AK and NDPK were also cell surfaceassociated ecto-nucleotidases. Using $\mathrm{AP}_{5} \mathrm{~A}$ as a probe for AK activity, $\left[{ }^{3} \mathrm{H}\right] \mathrm{ADP}$ conversion to $\left[{ }^{3} \mathrm{H}\right] \mathrm{AMP}$ was inhibited by $59 \%\left(0.51 \pm 0.05\right.$ versus $\left.0.21 \pm 0.03 \mathrm{nmol} / \mathrm{min} / \mathrm{cm}^{2}\right)$, the difference $\left(0.30 \mathrm{nmol} / \mathrm{min} / \mathrm{cm}^{2}\right)$ reflecting AK activity. To more directly demonstrate AK activity, the formation of $\left[{ }^{33} \mathrm{P}\right] \mathrm{ADP}$ from AMP and $\left[\gamma^{33} \mathrm{P}\right] \mathrm{ATP}$ was further quantitated on cell surfaces. Although specific for the AK reaction, this assay likely underestimates AK activity due to the concomitant presence of $\mathrm{AP}_{5} \mathrm{~A}$-insensitive $\mathrm{ADP}$ metabolism on cell surfaces. Despite this limitation, significant AK activity was indeed detected at the apical surface of nasal surface epithelial cells (Figure 5A).

To test whether the observed AK activity was strictly cell-associated or the result of released/shed enzymes, the formation of $\left[{ }^{33} \mathrm{P}\right] \mathrm{ADP}$ from $\left[\gamma^{33} \mathrm{P}\right] \mathrm{ATP}$ and AMP was

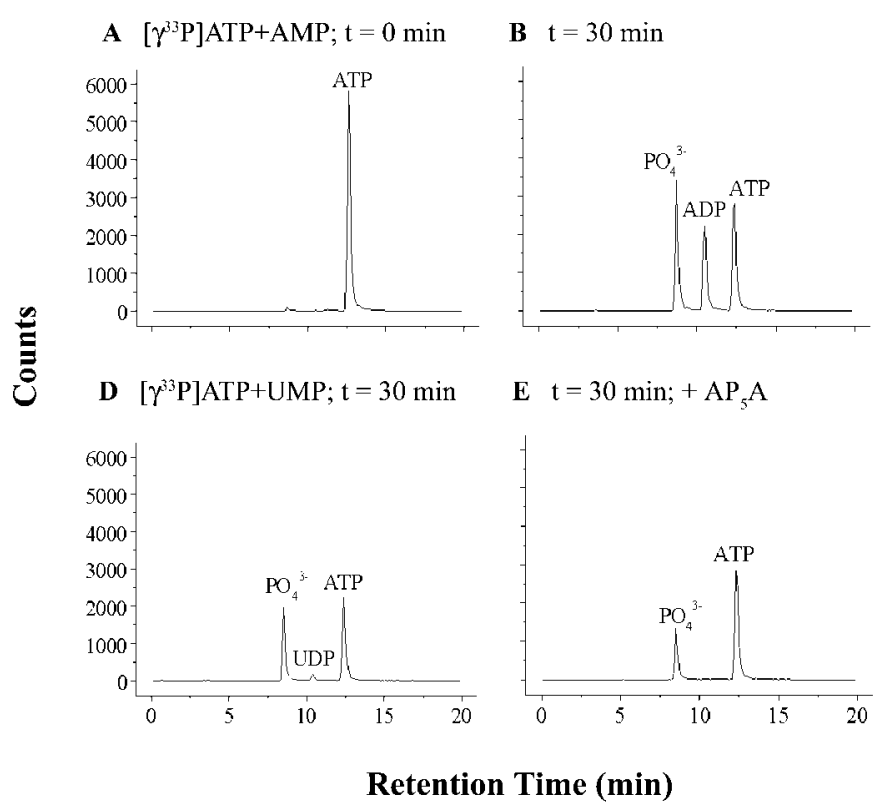

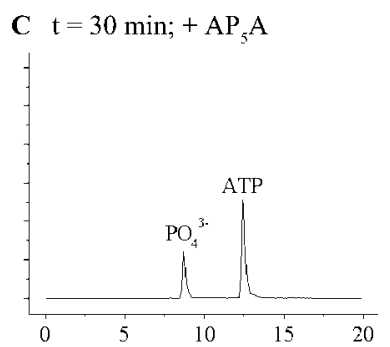

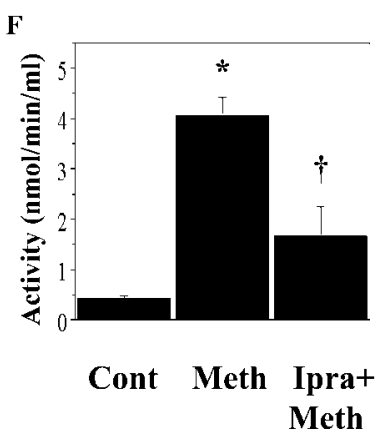

Figure 3. AK activity in SMG secretions: $A T P+A M P \leftrightarrow 2 A D P$. The formation of $\left[{ }^{33} \mathrm{P}\right] \mathrm{ADP}$ from $\left[\gamma^{33} \mathrm{P}\right] \mathrm{ATP}(0.1 \mathrm{mM})+$ AMP (0.1 $\mathrm{mM})$ confirmed the presence of $\mathrm{AK}$ in SMG secretions. $(A) \mathrm{At}$ $t=0$ min only $\left[\gamma^{33} \mathrm{P}\right]$ ATP was seen. (B) At $t=30 \mathrm{~min}$, the transfer of the $\gamma^{33}$-phosphate group from ATP to AMP resulted in the formation of $\left.{ }^{[3} \mathrm{P}\right] \mathrm{ADP} .(C)$ The addition of $\mathrm{AP}_{5} \mathrm{~A}(0.5 \mathrm{mM})$ to lavages completely blocked the formation of $\left.{ }^{33} \mathrm{P}\right]$ ADP; $t=30 \mathrm{~min}$. $(D)$ Minimal $\left[{ }^{33} \mathrm{P}\right]$ UDP is produced from $\left[\gamma^{33} \mathrm{P}\right] \mathrm{ATP}$ $(0.1 \mathrm{mM})+\operatorname{UMP}(0.1 \mathrm{mM})$ at $t=$ $30 \mathrm{~min}$, which was blocked $(E)$ by the addition of $\mathrm{AP}_{5} \mathrm{~A}(0.5 \mathrm{mM})$. Note the liberation of free $\mathrm{PO}_{4}{ }^{3-}$ $(B, C, D$, and $E)$ as the result of NTPase activity in SMG secretions. $(F)$ AK activity was quantitated in lavages collected under control conditions (Cont); after stimulating SMG secretion with methacholine (Meth) $(* P<0.001$ versus Cont); and with methacholine treatment after ipratropium bromide pretreatment (Ipra + Meth) $\left({ }^{\dagger} P=0.01\right.$ versus Meth) using $\left[{ }^{3} \mathrm{H}\right] \mathrm{ADP}(0.5 \mathrm{mM})$ as the starting substrate. 

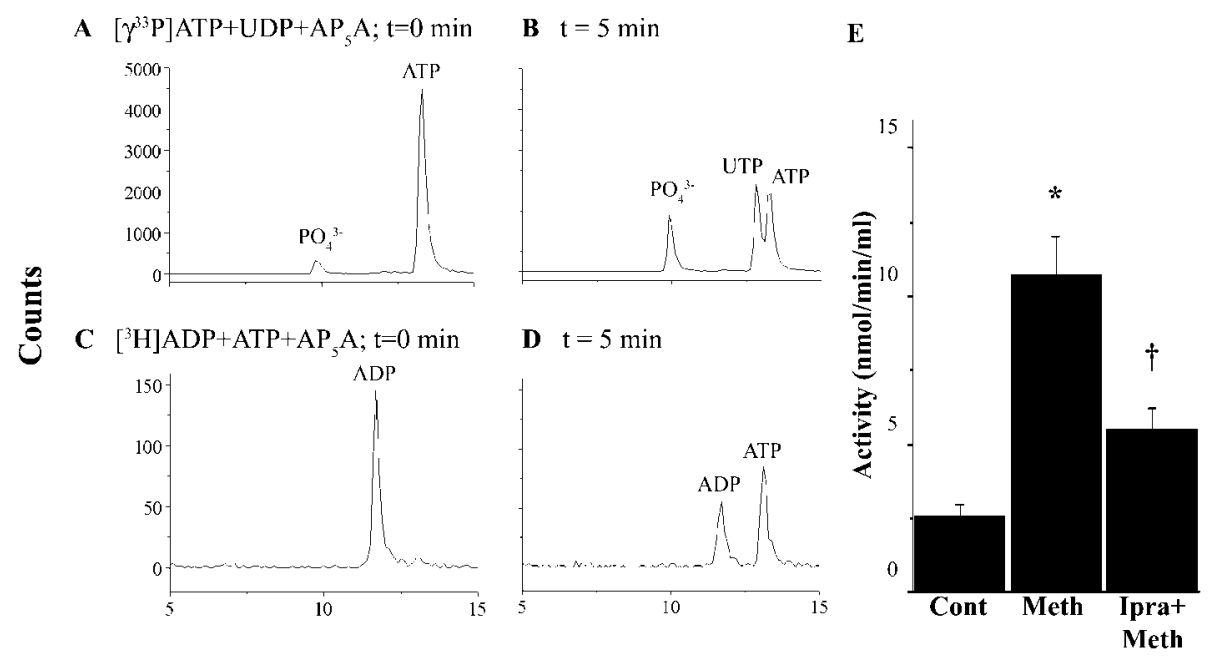

Figure 4. NDPK activity in SMG secretions: $X T P+Y D P \leftrightarrow X D P+Y T P$. NDPK activity in SMG secretions was demonstrated by adding $\left[\gamma^{33} \mathrm{P}\right]$ ATP $(0.5 \mathrm{mM})$ and unlabeled UDP $(0.1 \mathrm{mM})$ in the presence of $\mathrm{AP}_{5} \mathrm{~A}(1 \mathrm{mM})$ to block AK activity. $(A)$ At $t=0 \mathrm{~min}$, only the radiolabeled starting reactant is seen. ( $B$ ) At $t=5 \mathrm{~min}$, the formation of $\left[\gamma^{33} \mathrm{P}\right] \mathrm{UTP}$ was observed, as well as the liberation of free $\mathrm{PO}_{4}{ }^{3-}$ due to the concomitant presence of NTPase activity. NDPK activity was further demonstrated by adding $\left[{ }^{3} \mathrm{H}\right] \mathrm{ADP}(0.1 \mathrm{mM})+$ ATP $(0.05 \mathrm{mM})$ in the presence of $\mathrm{AP}_{5} \mathrm{~A}(1 \mathrm{mM}) .(C)$ At $t=0 \mathrm{~min}$ only the radiolabeled starting reactant is seen. (D) At $t=5 \mathrm{~min}\left[{ }^{3} \mathrm{H}\right]$ ATP formation was observed. $(E)$ Using these reaction conditions, NDPK activity was quantitated in lavages collected under control conditions (Cont); after stimulating SMG secretion with methacholine $($ Meth) $(* P<$ 0.001 versus Cont); and with methacholine treatment after ipratropium bromide pretreatment (Ipra + Meth) $\left({ }^{\dagger} P=0.02\right.$ versus Meth).

monitored in parallel experiments using conditioned media collected from the apical surface of cultures. After a 30-min preincubation in KBR, a majority of the AK activity was cell-associated, although a significant fraction of the total activity was contained in the conditioned media (Figure 5A). With increasing incubation times, conditioned media was found to contain progressively greater amounts of AK activity (Figure 5B).

NDPK activity was also assayed on the mucosic surface of well-differentiated airway epithelial cultures using the $\left[\gamma^{33} \mathrm{P}\right] \mathrm{ATP}+\mathrm{UDP} \rightarrow \mathrm{ADP}+\left[\gamma^{33} \mathrm{P}\right] \mathrm{UTP}$ reaction. Like AK, a majority of the NDPK activity was cell associated after a 30-min preincubation in KBR, although significant activity was also present in conditioned media collected from the apical compartment (Figure 5A). Once again, the amount of NDPK activity in conditioned media increased

$\mathbf{A}$

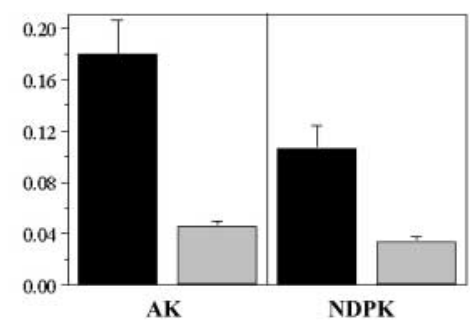

B

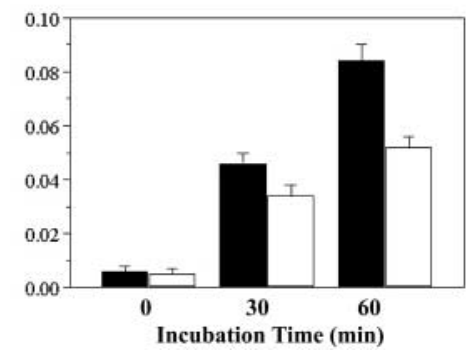

over time (Figure 5B). Of note, NTPase activity on cells confounded NDPK activity measurements, causing our measurements to underestimate total activity.

\section{Discussion}

Extracellular nucleotides, via their interaction with airway $\mathrm{P}_{2} \mathrm{Y}_{2}$ receptors, play an important role in regulating elements of the mucociliary clearance apparatus. The regulation of extracellular nucleotide concentrations is physiologically important, therefore, and involves both nucleotide release and metabolic pathways.

General schemes of extracellular nucleotide metabolism have included a role for (1) the E-NTPDase family (e.g., CD39 and CD39L1-CD39L5) in NTP and NDP hydrolysis; (2) the ecto-phosphodiesterase/nucleotide pyrophosphatase (PDNP) family for ATP, ADP, and dinucleotide metabolism; (3) alkaline phosphatase, with the capacity to dephosphorylate nucleoside 5'tri-, di- and monophosphates; and (4) ecto-5'nucleotidase, which hydrolyzes NMP to nucleoside (17). Once fully dephosphorylated, the resulting nucleosides may be scavenged by nucleoside transporters (18). In airways, a full characterization of the relevant ecto-nucleotidases has not been performed. Recent studies found evidence for an ecto-alkaline phosphodiesterase activity that was responsible for dinucleotide metabolism on well-differentiated airway cultures (19), and Lazarowski and colleagues demonstrated that ecto-NDPK activity is present on the apical and basolateral surfaces of primary airway epithelial cultures (20).

The complexity of nucleotide metabolic pathways in airways is further increased by the fact that ecto-nucleotidases are associated with both the superficial epithelium and submucosic gland secretions (10). In this study, we showed that SMG secretions contain robust AK and NDPK activities, in addition to the previously described NTPase activity. AK and NDPK activities were also detected on the apical surface of well-differentiated airway epithelial cultures. Interestingly, a significant proportion of this ac- 
tivity was released into the culture medium over time, suggesting either shedding of membrane-associated enzymes or the presence of an enzyme secretory pathway. The commonality of enzymes found in SMG secretions and on the surface of airway epithelial cells suggests that these "ectokinases" (AK and NDPK) might have an important role in extracellular nucleotide metabolism, which has not previously been recognized.

Most notable, perhaps, is the finding of ecto-AK activity in SMG secretions and on airway surfaces. AK catalyzes the reversible transfer of a phosphate group between ATP and AMP, forming ADP, and has traditionally been viewed as an intracellular enzyme responsible for the control of intracellular adenine nucleotide composition. Five mammalian isoforms have been identified to date (AK1-AK5), which are encoded by separate genes and include both mitochondrial and cytosolic forms. Precedent for a plasma membrane isoform is scant and comes from reports of ecto-AK activity in human umbilic vein endothelic cells (HUVEC) (21), synaptosomic brain preparations (22), and an innervated frog muscle preparation (23). As a consequence, AK is not often considered when extracellular nucleotide metabolism is studied. Importantly, its activity can be missed when nucleotide metabolism assays rely on the liberation of free phosphate and when ATPase and/or ADPase activities are also present. Utilization of HPLC to assay reaction products, and $\mathrm{AP}_{5} \mathrm{~A}$ as a specific inhibitor of $\mathrm{AK}(11)$, permits detection of $\mathrm{AK}$ when significant activity is present.

Nucleoside diphosphokinase, another enzyme that traditionally has been viewed as an intracellular regulator of nucleotide pools, was also found to play a role in extracellular nucleotide metabolism in airways. The notion of an ectoNDPK was initially raised by multiple reports of nm-23anti-metastasis gene products (24), which encode NDPK isoforms expressed at the cell surface (25). Further evidence for an ecto-NDPK comes from recent reports that demonstrated NDPK activity on the surface of a variety of cells, including primary human nasal epithelial cells $(20), 16 \mathrm{HBE}^{-14 \mathrm{o}^{-}}$human bronchial epithelial cells (16), and HUVEC cells (21). Because a single cell type may possess more than one P2nucleotide receptor species with different nucleotide agonist selectivity, it has been speculated that ecto-NDPK may alter the balance of extracellular nucleotide species, and thereby effect signaling through P2 receptors (26). For example, ATP released into the extracellular milieu may donate its terminal phosphate group to a UDP molecule in the same compartment, thus forming UTP and allowing activation of the UTP-selective $\mathrm{P}_{2} \mathrm{Y}_{4}$ receptor (16).

Understanding the impact of AK and NDPK on extracellular nucleotide metabolism within the larger framework of ecto-nucleotidases on airway surfaces is an important, though complicated, issue. In the context of a complex system of enzymes, the role that individual components play will depend upon several variables, including enzyme $K_{m}$ and $\mathrm{V}_{\max }$. The enzyme $\mathrm{V}_{\max }$, in turn, is proportional to the abundance of the enzyme and its $\mathrm{K}_{\mathrm{cat}}$. In addition, because AK and NDPK each utilize two substrate molecules, the concentration of individual nucleotide substrates in the local milieu is an important determinant of activity. Because the reported $\mathrm{K}_{\mathrm{m}}$ values $(\sim 100 \mu \mathrm{M})$ for $\mathrm{AK}(21,27)$ and NDPK (15) are similar to those of other airway ecto-nucle- otidases (28), the impact that these enzymes have on extracellular nucleotide metabolism will depend primarily on the enzyme $\mathrm{V}_{\max }$ and substrate concentrations.

In the experimental systems we have studied (i.e., surface epithelial cells and submucosic gland secretions), the relative importance of AK and NDPK varies. On surface epithelial cells, E-NTPases have $\sim 10$-fold higher activity (10) than AK and NDPK and so will likely serve as the major pathway for NTP degradation. With regard to ADP metabolism, however, $>50 \%$ of surface epithelial cell ADP metabolism was inhibited by $\mathrm{AP}_{5} \mathrm{~A}$, suggesting that AK significantly contributes to the metabolism of this nucleotide at this site. NDPK, on the other hand, will primarily serve to distribute phosphate groups among available nucleotide species.

In human nasal lavage samples, however, a very different profile of nucleotidase activities was observed. NDPK and $\mathrm{AK}$ activities were much greater than that of the E-NTPase (10) ( 30-fold and 6-fold, respectively) in nasal lavages collected under unstimulated conditions. After stimulating glandular secretion with methacholine, all three enzyme activities significantly increased, although NDPK acitivity continued to dominate (NDPK $>\mathrm{AK} \approx$ NTPase). In contrast to the pattern seen on superficial epithelial cells, ADP metabolism was entirely sensitive to $\mathrm{AP}_{5} \mathrm{~A}$. This result suggests that $\mathrm{AK}$ is essential for ADP metabolism in SMG secretions and that the secreted E-NTPase strongly prefers NTP species over NDPs.

The relative importance of secreted versus cell-attached nucleotidases in NTP metabolism on airway surfaces in vivo is difficult to assess because the relative contribution of submucosal glands and superficial epithelia to airway surface liquid volume/composition is generally unknown and likely to be extremely variable. In lung regions that are heavily populated with submucosal glands (proximal airways), especially under conditions that increase the rate of SMG secretion (see below), extracellular nucleotide metabolism may be profoundly affected, or even dominated, by nucleotidases contained in SMG secretions. In these regions, the secreted NTPase will contribute to NTP metabolism, whereas AK is expected to prevent the buildup of ADP when coupled to the actions of this NTPase. The importance of NDPK in these systems relies on its ability to transfer phosphate groups between different nucleotide species and thus potentially alter the pattern of nucleotide receptor activation $(15,16)$.

The finding that nucleotide-metabolizing enzymes are secreted from submucosal glands provides new insights into the regulatory processes that limit airway nucleotide receptor activation. For example, one may speculate that gland secretions provide a reserve capacity for nucleotide metabolism. In the setting of airway inflammation/irritants, where nucleotide levels are expected to be elevated due to cellular breakdown, stimulated gland secretion may provide a means to regulate ATP and ADP levels through the combined actions of the secreted NTPase (10) and AK. These activities, in turn, may prevent prolonged nucleotide receptor stimulation and/or desensitization. Whether diseases characterized by pathologic gland hypersecretion, e.g., chronic bronchitis, have reduced nucleotide levels in vivo is worth exploring given the potential ramifications of 
reduced ATP levels on mucociliary clearance. The impact that secreted nucleotidases have on nucleotide-based therapies for lung diseases will also need to be considered.

The finding of secreted nucleotidases in a biologic system is not a unique phenomenon. In other tissues with exocrine glands, such as oviduct $(29,30)$ and prostate $(31$, 32 ), the secretion of an ATPase has previously been observed. In these tissues, enzyme secretion is mediated via "shedding" of vesicular material (33). In addition, release of an ATPase from nerve terminals upon electric stimulation has been described (34). It is possible, therefore, that the secretion of nucleotidases from nasal submucosal glands may occur either via microvesicular shedding from epithelial cell surfaces or through a classic exocytotic pathway. The mechanism underlying the release of surfaceassociated nucleotidases in our cultured epithelial preparations is also unclear. A similar phenomenon, including the release of both an ATPase and 5'-nucleotidase, has been observed in endothelial cells in response to shear stress (35). Our data demonstrate for the first time, however, that nucleotidase secretion can be mediated by receptor activation. This finding raises the question whether other tissues that respond to cholinergic stimulation may release nucleotidases in a similar fashion.

The identification of ecto-NDPK and ecto-AK as potentially important determinants of extracellular nucleotide concentrations furthers our knowledge of the regulatory processes that influence nucleotide-mediated signaling in airways. Future studies focusing on molecular identification of specific ectonucleotidases/ecto-kinases in airways, the biochemic characterization of the integrated system at physiologic substrate concentrations, and of cell biologic processes that determine cell surface enzyme expression and/or secretion should greatly improve our understanding of this complex enzyme system.

Acknowledgments: The authors would like to acknowledge Dr. Eduardo Lazarowski for his thoughtful discussions and insights. This work was supported by a grant from the Cystic Fibrosis Foundation (L543).

\section{References}

1. Cressman, V. L., E. Lazarowski, L. Homolya, R. C. Boucher, B. H. Koller, and B. R. Grubb. 1999. Effect of loss of P2Y(2) receptor gene expression on nucleotide regulation of murine epithelial $\mathrm{Cl}(-)$ transport. J. Biol. Chem. 274:26461-26468.

2. Brown, H. A., E. R. Lazarowski, R. C. Boucher, and T. K. Harden. 1991. Evidence that UTP and ATP regulate phospholipase C through a common extracellular 5'-nucleotide receptor in human airway epithelial cells. Mol. Pharmacol. 40:648-655.

3. Homolya, L., W. C. Watt, E. R. Lazarowski, B. H. Koller, and R. C. Boucher. 1999. Nucleotide-regulated calcium signaling in lung fibroblasts and epithelial cells from normal and P2Y(2) receptor (-/-) Mice. J. Biol. Chem. 274:26454-26460.

4. Stutts, M. J., J. G. Fitz, A. M. Paradiso, and R. C. Boucher. 1994. Multiple modes of regulation of airway epithelial chloride secretion by extracellular ATP. Am. J. Physiol. 267:C1442-C1451.

5. Weiss, T., L. Gheber, V. Shoshan-Barmatz, and Z. Priel. 1992. Possible mechanism of ciliary stimulation by extracellular ATP: involvement of calcium-dependent potassium channels and exogenous $\mathrm{Ca}^{2+}$. J. Membr. Biol. 127:185-193.

6. Lethem, M. I., M. L. Dowell, M. Van Scott, J. R. Yankaskas, T. Egan, R. C. Boucher, and C. W. Davis. 1993. Nucleotide regulation of goblet cells in human airway epithelial explants: normal exocytosis in cystic fibrosis. Am. J. Respir. Cell Mol. Biol. 9:315-322.

7. Bennett, W. D., K. N. Olivier, K. L. Zeman, K. W. Hohneker, R. C. Boucher, and M. R. Knowles. 1996. Effect of uridine 5'-triphosphate plus amiloride on mucociliary clearance in adult cystic fibrosis. Am. J. Respir. Crit. Care Med. 153:1796-1801.

8. Ma, W., A. Korngreen, N. Uzlaner, Z. Priel, and S. D. Silberberg. 1999. Extracellular sodium regulates airway ciliary motility by inhibiting a P2X receptor. Nature 400:894-897.
9. Taylor, A. L., L. M. Schwiebert, J. J. Smith, C. King, J. R. Jones, E. J. Sorscher, and E. M. Schwiebert. 1999. Epithelial P2X purinergic receptor channel expression and function. J. Clin. Invest. 104:875-884.

10. Donaldson, S. H., E. R. Lazarowski, M. Picher, M. R. Knowles, M. J. Stutts, and R. C. Boucher. 2000. Basal Nucleotide Levels, Release, and Metabolism in Normal and Cystic Fibrosis Airways. Mol. Med. 6:969-982.

11. Lienhard, G. E., and I. I. Secemski. 1973. P 1,P 5 -Di(adenosine-5')pentaphosphate, a potent multisubstrate inhibitor of adenylate kinase. J. Biol. Chem. 248:1121-1123.

12. Gray, T. E., K. Guzman, C. W. Davis, L. H. Abdullah, and P. Nettesheim. 1996. Mucociliary differentiation of serially passaged normal human tracheobronchial epithelial cells. Am. J. Respir. Cell Mol. Biol. 14:104-112.

13. Van Rompay, A. R., M. Johansson, and A. Karlsson. 2000. Phosphorylation of nucleosides and nucleoside analogs by mammalian nucleoside monophosphate kinases. Pharmacol. Ther. 87:189-198.

14. Postel, E. H. 1998. NM23-NDP kinase. Int. J. Biochem. Cell Biol. 30:1291-1295.

15. Lazarowski, E. R., L. Homolya, R. C. Boucher, and T. K. Harden. 1997. Identification of an ecto-nucleoside diphosphokinase and its contribution to interconversion of P2 receptor agonists. J. Biol. Chem. 272:20402-20407.

16. Lazarowski, E. R., R. C. Boucher, and T. K. Harden. 2000. Constitutive release of ATP and evidence for major contribution of ecto-nucleotide pyrophosphatase and nucleoside diphosphokinase to extracellular nucleotide concentrations. J. Biol. Chem. 275:31061-31068.

17. Zimmermann, H. 1999. Two novel families of ectonucleotidases: molecular structures, catalytic properties, and a search for function. Trends Pharmacol. Sci. 20:231-236.

18. Cass, C. E., J. D. Young, S. A. Baldwin, M. A. Cabrita, K. A. Graham, M. Griffiths, L. L. Jennings, J. R. Mackey, A. M. Ng, M. W. Ritzel, M. F. Vickers, and S. Y. Yao. 1999. Nucleoside transporters of mammalian cells. Pharm. Biotechnol. 12:313-352.

19. Picher, M., and R. C. Boucher. 2000. Biochemical evidence for an ecto alkaline phosphodiesterase I in human airways. Am. J. Respir. Cell Mol. Biol. 23:255-261.

20. Lazarowski, E. R., A. M. Paradiso, W. C. Watt, T. K. Harden, and R. C. Boucher. 1997. UDP activates a mucosal-restricted receptor on human nasal epithelial cells that is distinct from the P2Y2 receptor. Proc. Natl. Acad. Sci. USA 94:2599-2603.

21. Yegutkin, G. G., T. Henttinen, and S. Jalkanen. 2001. Extracellular ATP formation on vascular endothelial cells is mediated by ecto-nucleotide kinase activities via phosphotransfer reactions. FASEB J. 15:251-260.

22. Nagy, A. K., T. A. Shuster, and A. V. Delgado-Escueta. 1989. Rat brain synaptosomal ATP:AMP-phosphotransferase activity. J. Neurochem. 53:1166-1172.

23. Cascalheira, J. F., and A. M. Sebastiao. 1992. Adenine nucleotide analogues, including gamma-phosphate-substituted analogues, are metabolised extracellularly in innervated frog sartorius muscle. Eur. J. Pharmacol. 222:49-59.

24. Rosengard, A. M., H. C. Krutzsch, A. Shearn, J. R. Biggs, E. Barker, I. M. Margulies, C. R. King, L. A. Liotta, and P. S. Steeg. 1989. Reduced Nm23/ Awd protein in tumour metastasis and aberrant Drosophila development. Nature 342:177-180.

25. Urano, T., K. Furukawa, and H. Shiku. 1993. Expression of nm23/NDP kinase proteins on the cell surface. Oncogene 8:1371-1376.

26. Harden, T. K., E. R. Lazarowski, and R. C. Boucher. 1997. Release, metabolism and interconversion of adenine and uridine nucleotides: implications for G protein-coupled P2 receptor agonist selectivity. Trends Pharmacol. Sci. 18:43-46.

27. van Rompay, A. R., M. Johansson, and A. Karlsson. 1999. Identification of a novel human adenylate kinase. cDNA cloning, expression analysis, chromosome localization and characterization of the recombinant protein. Eur. J. Biochem. 261:509-517.

28. Picher, M., and R. C. Boucher. 2001. Metabolism of extracellular nucleotides in human airways by a multienzyme system. Drug Dev. Res. 52:66-75.

29. Strobel, R. S., A. K. Nagy, A. F. Knowles, J. Buegel, and M. D. Rosenberg. 1996. Chicken oviductal ecto-ATP-diphosphohydrolase: purification and characterization. J. Biol. Chem. 271:16323-16331.

30. Nagy, A. K., A. F. Knowles, and G. T. Nagami. 1998. Molecular cloning of the chicken oviduct ecto-ATP-diphosphohydrolase. J. Biol. Chem. 273: 16043-16049.

31. Beaudoin, A. R., A. Vachereau, G. Grondin, P. St-Jean, M. D. Rosenberg, and R. Strobel. 1986. Microvesicular secretion, a mode of cell secretion associated with the presence of an ATP-diphosphohydrolase. FEBS Lett. 203:1-2.

32. Ronquist, G., and I. Brody. 1985. The prostasome: its secretion and function in man. Biochim. Biophys. Acta 822:203-218.

33. Beaudoin, A. R., and G. Grondin. 1991. Shedding of vesicular material from the cell surface of eukaryotic cells: different cellular phenomena. Biochim. Biophys. Acta 1071:203-219.

34. Todorov, L. D., S. Mihaylova-Todorova, T. D. Westfall, P. Sneddon, C. Kennedy, R. A. Bjur, and D. P. Westfall. 1997. Neuronal release of soluble nucleotidases and their role in neurotransmitter inactivation. Nature 387:76-79.

35. Yegutkin, G., P. Bodin, and G. Burnstock. 2000. Effect of shear stress on the release of soluble ecto-enzymes ATPase and 5'-nucleotidase along with endogenous ATP from vascular endothelial cells. Br. J. Pharmacol. 129:921-926. 